\title{
PRICING IN THE HOTEL AND CATERING SECTOR**
}

\section{INTRODUCTION}

Pricing behaviour in the services has received little attention in economic literature. See Nooteboom, Kleijweg and Thurik (1987) for a few references in this area. The main question is whether pricing behaviour can be explained in the context of a plausible economic model using quantitative data. In the present paper this will be studied for the hotel and catering sector. As a starting point we use a cost-mark-up model developed by Nooteboom (1985) for the retail sector. The advantage of the nontraditional model is that it is simple, easy to test and often corroborated. See Nooteboom (1985), Nooteboom and Thurik (1985) and Nooteboom, Thurik and Vollebregt (1986). The disadvantage of the model is that no specific demand and supply effects are distinguished the model is developed in a reduced form) and there is no theoretical micro-economic foundation yet. The advantage of the model over other cost-mark-up models (cf. Weintraub (1978), Sylos-Labini (1979) and Dutkowsky and Gianturco (1986)) is that mark-up differences are explicitly explained. In this way one can test whether price-setting is cost-oriented, market-oriented or a mixture. Moreover, the empirical results obtained with the model are convincing. Despite various straightforward dissimilarities between retailing and the hotel and catering sector, we shall use the model as a starting point to increase our knowledge of its performance in the services as a whole. This is worth while in view of the importance of the service industries for the economy as a whole (cf. Gershuny and Miles (1984) and Snel (1986)).

Although we have to reject the hypothesis of mark-up pricing in the hotel and catering sector, the model proves a useful instrument to discriminate between such influences as sales composition, costs and their various components, scale and demand conditions on price setting. Our empirical evidence stems from the Dutch hotel and catering sector (1977 through 1981).

* Research Institute for Small and Medium-Sized Business, Dept. of Fundamental Research, P.O. Box 7001, 2701 AA Zoetermeer, The Netherlands.

** We are extremely grateful to the Central Bureau of Statistics (particularly the Department of Interior Trade and Commercial Services) in Voorburg, The Netherlands for permitting the use of their data under certain secrecy conditions. 


\section{PRICING IN THE HOTEL AND CATERING SECTOR}

In the literature about the hotel and catering sector no quantitative studies concerning pricing behaviour have been found. However, in a descriptive way several enumerations of pricing methods are given in, for example, Anthea Rogers (1980), Keller (1970), Kotas (1975), whereas Kreul (1982) refers to various textbooks. The main pricing methods used in practise appear to be: cost-plus pricing, rate of return pricing, contribution pricing and backward pricing (see Anthea Rogers). The marketing literature in services does not provide decisive hints either ( $c f$. Rathmell (1974), Lovelock (1984) and Kotler and Bloom (1984)), primarily because of the heterogeneity within the services and the absence of empirical evidence.

It is not our intention to compare these four methods in a quantitative study. We select the cost-plus pricing method because:

- the method has been successfully applied elsewhere. These applications refer to retailing, an industry with several similarities to the hotel and catering sector. Similarities and discrepancies between the two sectors will be dealt with below;

- the relevance of average cost based pricing is mentioned in two surveys.

1. Anthea Rogers (1980, pp 249, 250) discusses a survey (1974) which revealed that all four pricing methods were used somewhere in the hotel business and that pricing behaviour in general was closely related to the form of ownership and size of the hotels. However, most of the establishments appeared to use cost-oriented approaches;

2. in a survey of the Dutch hotel and catering sector covering 206 businesses in 1983 the cost-plus pricing method is said to be used by $41 \%$ of the entrepreneurs, half of which used the purchasing costs as a basis, and the other half the total average costs. Cf. Van Hest (1983, pp 14, 15);

- when dealing with the service industries in general, the marketing literature points at cost-based or rate of return-based pricing (the latter being another manifestation of cost-based pricing) instead of competition-based or demand-based pricing. $C f$. Rathmell (1974).

We now return to a comparison between retailing and the hotel and catering sector, emphasizing similarities and differences regarding their pricing behaviour. Usually, retailing is not considered to be part of the service industries, but is regarded as part of the distributive trades. However, there are various similarities:

- both sectors are characterized by supplying space capacity to visiting customers to provide their services. Service in retailing is the provision of the opportunity to buy goods, whereas service in the hotel and catering sector consists of providing rooms, meals, drinks, etc. In absence of demand the provider of the service has a lack of business and the provider cannot form any stocks: the performance of the service coincides temporally with its consumption. The product of service industries in general cannot be stored in contrast to that of manufacturing industries; 
- in both sectors space capacity and its furniture are designed to attract customers. Non-price competition is used to differentiate an establishment from its competitors: atmosphere, decor, status and prestige are important characteristics;

- because of the dependency of visiting customers both service sectors are $s u b$ ject to fluctuating demand and, possibly, congestion. Demand is time-dependent with significant fluctuations that are unpredictable to a certain degree;

- firms in retailing and the hotel and catering sector operate in a spatial monop$o l y$, in the sense that there are spatial bounds to their potential market and competition from outside this market is limited.

There are also important differences between retailing and the hotel and catering sector:

- the most important difference between the retailing and the hotel and catering sector is that a retail customer leaves the outlet with material goods which he is going to consume afterwards. Alternatively, these goods could be offered for sale. A customer of a hotel or catering outlet does not leave with a material good. He can only be (dis)satisfied by a feeling of a well-spent night, a good meal or a hangover. Both services are 'consumed' or received in the outlet, but the share of the mere transfer of the physical entities in the total service is larger in retailing than in the hotel and catering sector;

- in a part of the hotel and catering sector it is usual to control customers' arrivals (with a reservation system), or to manipulate their arrivals by price differentiation;

- congestion is sometimes an attraction factor in the hotel and catering sector as far as it is associated with atmosphere; in retailing, however, its influence is generally supposed to be negative.

In our view these differences weaken the relation between prices and costs in the hotel and catering sector. The customers' experience of the service quality is also a matter of intangibles which need not be directly related to costs. Moreover, temporal price differention may reduce the cost orientation of pricing.

In addition to the theoretical considerations given above, some empirical evidence will be given in the framework of Nooteboom's mark-up model. This model defines the average percentage gross margin (defined as the diference between sales and purchase value of sales, as a percentage of sales) per establishment type $(m)$ as a mark-up $(r)$ on average percentage operating costs excluding a reward for the shopkeeper's labour $(k)$. Formally,

$$
m_{i} \triangleq k_{i}+r_{i}
$$

where $i$ refers to the establishment type and where the mark-up, $r$, depends on various influences to be discussed elsewhere in this paper. The mark-up, $r$, like $m$ and $k$, is expressed as a percentage of sales.

Now, Exhibit 1 shows a scatterplot of $m$ against $k$ for averages per shop-type in the retailing business, and for averages in the hotel and catering sector, for 
1980 in The Netherlands. The averages are taken from three types of trade (hotels, restaurants and cafés) and they represent various size groups (see section 4). The dashed line indicates the relationship $m=k$.

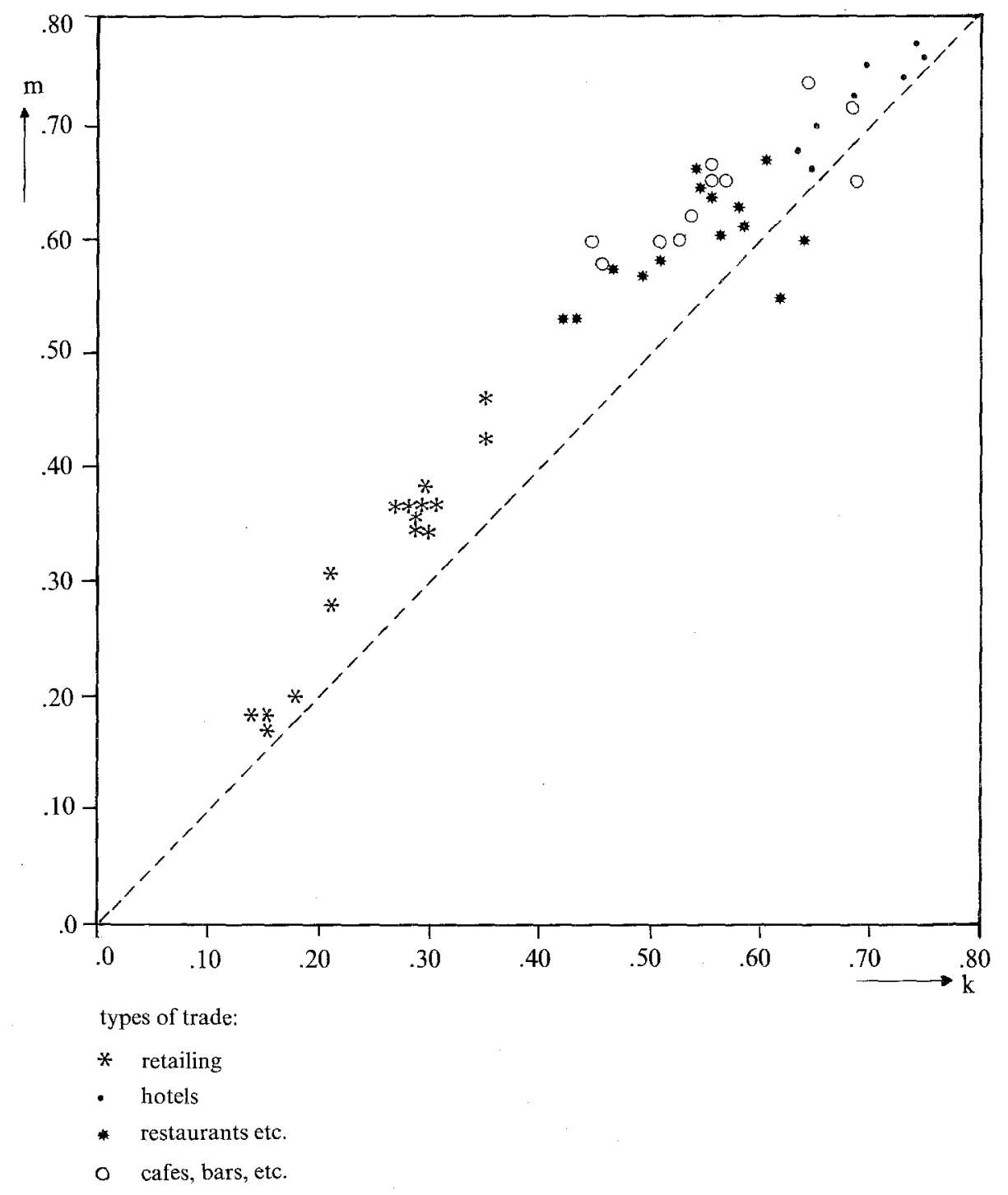

Exhibit $1-M$ (average percentage gross margin) against $K$ (average percentage operating costs excluding a reward for entrepreneurial labour) for averages per shop-type in retailing and for averages per size group and type of trade in the hotel and catering sector (see section 4) 
We observe that:

- both $k$ and $m$ are significantly lower in retailing than in the hotel and catering sector. This is due to the fact that the percentage purchase value in the hotel and catering sector is relatively low;

- the 'slopes' of the scatterplots appear to differ: the slope seems to be less steep in the hotel and catering sector than in retailing. This may point to a weakened influence of costs on margins.

The shape of the scatterplot stresses one of the differences between retailing and the hotel and catering sector: mere transfer of goods hardly exists in the hotel sector. It only occurs when it comes to the selling of food, beverages, etc. Moreover, the transferred goods often consist rather of transformed ingredients, e.g. a meal. The purchase value of sales in the hotel and catering sector will be relatively low when compared to that in retailing. Also the discrimination between purchases and costs becomes blurred. We define costs to include: wages, taxes, interests, rents, depreciation, energy, water, etc. All remaining (material) costs are assumed to be 'purchases'. In equations (la) and (2a) the different role of purchases and costs will be further illustrated.

In spite of the theoretical and empirical warnings, we want to test Nooteboom's mark-up model against our hotel and catering data. We do so because cost-based pricing seems to be a relevant policy. Furthermore, confrontation with hotel and catering data may increase our knowledge of the mark-up relationship, which up till now has only been tested for retailing. In the next section this relationship as well as some extensions will be dealt with.

\section{THE MARK-UP MODEL}

As explained in the previous section, our point of departure is a relationship developed by Nooteboom. For theoretical and empirical evidence see Nooteboom (1985). Average percentage gross margin $(m)$ per type of shop is treated as a sum of the average percentage operating costs $(k)$ excluding the reward for the shopkeeper's labour and a mark-up ( $r$ ). The (profit) mark-up is supposed to consist of four parts. The first part secures a certain minimal average reward for the shopkeeper's labour. The second is a reflection of the influence of the nature of the product/service package in the shop-type, the third and fourth reflect the development of the market share of the shop-type (which is an indication of the competitive strength of the shop-type with respect to competing shop-types) and the growth of consumer spending. For the basic reward part the reciprocal value of average sales per shop is used, because a certain fixed, sales-independent, reward in guilders is achieved by a high percentage of sales if average sales are low and a low percentage of sales if average sales are high. The income elasticity is used to describe the product/service package. Nooteboom and Thurik (1985) and Nooteboom, Kleijweg and Thurik (1987), 
however, use average value of stock as a percentage of annual sales. The relationship, used for both intertype and time-series studies, reads:

$$
m_{i t} \triangleq k_{i t}+r_{i t}
$$

with

$$
r_{i t}=a_{1} \frac{1}{Q_{i t}}+a_{2} e_{i t}+a_{3} M A_{i t}+a_{4} \dot{C} B_{i t}
$$

where:

$i \quad$ : index of the shop-type;

$t$ : index of the year;

$m$ :average percentage gross margin;

$k$ : average percentage operating costs excluding the reward for shopkeeper's labour;

$Q$ : average sales size per shop in deflated prices;

$e \quad$ : income elasticity of the products and services offered;

$M A$ : change of market share;

$\dot{C} B$ : percentage change of consumer spending (in volume).

Coefficients to be estimated are $a_{1}>0, a_{2}>0, a_{3}>0$, and $a_{4}>0$, where $a_{1}$ is the fixed, sales independent share in average net margin:

$$
(m-k) Q=a_{1}+Q \cdot\left(a_{2} e+a_{3} M A+a_{4} \dot{C} B\right) .
$$

If a coefficient was appended to percentage costs, in most studies it was estimated at unity as postulated by the theory of a mark-up. In some studies an intercept, $a_{0}$, was included as a test of whether the profit mark-up contains a fifth part which is independent of costs, size, income elasticity, development of market share and consumer spending and equal for all shop-types. In most cases the intercept was estimated to be zero. $C f$. Nooteboom (1985) and Nooteboom and Thurik (1985).

Average percentage gross margin is defined as the difference between sales and purchase value of sales, taken as a percentage of sales value. It is considered as a price for services containing compensations for operating costs and entrepreneurial labour (risk, investment, etc.). The selling price can be deduced from profit mark-up, purchase price and operating costs. The relationship between average percentage gross margin and selling price is illustrated as follows: for a monoproduct firm average percentage gross margin is by definition:

$$
m=\frac{(p-v) q}{p q}
$$


where:

$p$ : selling price per item:

$v$ : purchase price per item;

$q$ : number of items sold.

Then it is easy to derive that equation (1) is equivalent to

$$
p=\frac{1}{1-r}(v+c)
$$

where:

$c$ : operating costs per item.

\section{DATA}

Use is made of the micro-data of the Produktiestatistieken Dienstverlening, Hotels, Restaurants, Café's, e.d. (Production statistics for Commercial Services, Hotels, Restaurants, Café's, etc.) of the Central Bureau of Statistics (CBS) in The Netherlands. Data are available for the years 1977 through 1981 (5 years). A brief description of the data is given in the CBS publications (1980a, 1980b and 1980c) and CBS (1981), CBS (1982) and CBS (1983). One of the objectives of these publications is to give a statistical description of the contribution of (the different types of trade within) the hotel and catering sector to national income. A stratified sampling method is applied to get accurate results using a limited number of enterprises. The number of enterprises of the sample per year is about 1200 enterprises on a population of about 23000 enterprises.

The types of trade are distinguished according to their main activity: enterprises providing food/meals, those providing beverages/drinks or those providing accommodation. This partitioning is also used in our study and we distinguish between the following three types of trade: restaurants, lunchrooms, cafeterias and snackbars (in the following indicated by 'restaurants'); cafés, bars, dance halls and nightclubs (in the following indicated by 'cafés'); and hotels.

Enterprises are grouped together per type of trade and per year according to sales size (in volume). For the restaurants 14 size groups are distinguished ( 9 for the restaurants, 5 for the cafeterias, lunchrooms and snackbars); for the cafés 11 size groups ( 6 for the cafés and 5 for the bars, dance halls and nightclubs) and for the hotels 8 size groups are distinguished. This is done for all five years. We refer to Van der Hoeven and Thurik (1986) for further details about the data construction.

\section{SPECIFICATION}

In this section we introduce some adjustments of the mark-up relationship in 
view of the specific nature of the hotel and catering sector, data limitations and some recent research results.

First, we want to delete income elasticity, development of market share and consumer spending from our mark-up relationship. The influence of the product/service package will be dealt with using a description of the sales composition because of the difficulty of establishing unambiguous values for the income elasticity. The development of the market share is deleted because no data are available on the level of size groups per type of trade. Moreover, it is questionable whether market share is a meaningful variable in our case. For retailing it is a reflection of the stage in the life cycle of a certain group of shops (shoptype); it is doubtful whether the life cycle of a size group of, let us say, the hotel sector is something that is recognized by entrepreneurs in the sense that it influences their pricing behaviour. The development of consumer spending is deleted for the time being because our time series is relatively short ( 5 years) and the data used for this variable seem to be less accurate then those for the remaining, supply variables. We shall return to the study of demand conditions in a later phase of our research (see sections 6 and 7), because our main goal is to investigate whether the cost-mark-up model applies also to the hotel and catering sector. In this phase of our study we shall not use our demand variable rather than use it badly.

We then have the following relationship:

$$
m=b_{0}+b_{1} k+b_{2} \frac{1}{Q}
$$

where time and type of trade/size group indices are deleted.

If $b_{1}=1$, equation (2) expresses a mark-up model in which the mark-up contains a size-independent part, $b_{0}$, and a size-dependent part, $b_{2}$. In a manner similar to that of equations (1) and (1a) it can be shown that (for a monoproduct firm) equation ( 2 ) is equivalent to

$$
p=\frac{1}{1-b_{0}}\left(v+b_{1} c+b_{2} \frac{1}{q}\right)
$$

where:

$q$ : number of items sold $(Q=p q)$.

First, we want to incorporate the results of two recent studies to deal with costs in a mark-up model. Subsequently, we want to explain how we treat the influence of the product/service package.

In their microlevel study on the explanation of the percentage average of gross margin Bode, Koerts and Thurik (1986) use an extension of the mark-up model, and they raise the question of whether shopkeepers make a distinction between what they call out-of-pocket operating costs and remaining operating costs in their pricing behaviour. It is possible that depreciation or family labour 
(valued at normal wage rates) are not passed on completely. The presence in our sample of some averages with a gross margins smaller than the total operating costs, $m<k$, (see Exhibit 1), appears to support the hypothesis of Bode, Koerts and Thurik that total operating costs are not passed on completely in establishing prices.

In the present study a similar subdivision of total operating costs is used. Total costs are partitioned into actual operating costs and calculated operating costs, the latter being depreciation costs and family labour (valued similarly to the procedure described in Van der Hoeven and Thurik (1985) where a model is given explaining the remuneration of family labour). This partitioning is used to study possible differences of their influences on pricing behaviour in the hotel and catering sector. Therefore, $b_{1} k$ in equation (2) is replaced by $b_{11} k r+$ $b_{12} k c$ where: $k r$ is the actual operating costs and $k c$ is the calculated operating costs respectively. Clearly, $k=k r+k c$.

Nooteboom, Kleijweg and Thurik (1987) use the mark-up relationship to investigate demand effects in pricing behaviour. They discriminate between total operating costs and normal costs, the latter being decycled total trend costs. Thurik and Kleijweg (1986) report a small adjustment lag in the use of labour to the development of sales resulting in procyclical labour productivity. Nonlabour costs (occupancy costs, etc.) are assumed to be less adjustable to demand than labour costs, so that total operating costs may be assumed to contain a significant procyclical part. Nooteboom, Kleijweg and Thurik (1987) study to what extent this part is passed on for price setting. They define normal costs as the trend value of total operating costs per shop-type. We shall also study the influence of normal costs replacing $b_{1} k$ in relationship (2) by $b_{3} k n+b_{4}(k-k n)$ where $k n$ represents average percentage normal costs, and $(k-k n)$ the short-term part of costs assumed to depend upon business cycle and fortuitous effects.

In addition, the influence of the product/service package is treated as follows. If equation (2) is multiplied by $Q$, the absolute gross profit (in value) is seen to consist of a fixed percentage, $b_{0}$, of the sales value, a fixed percentage, $b_{1}$, of the total operating costs and a third part, $b_{2}$, independent of both sales value and total operating costs. (Following Nooteboom, $b_{2}$ may be associated with the minimal, basic manager's/owner's labour reward).

$$
G P=b_{0} Q+b_{1} K+b_{2}
$$

where:

$G P:$ gross profit $(G P=m \times Q)$;

$Q$ : sales value;

$K$ : total operating costs.

In view of considerable variation of the sales composition across the hotel and catering sector, it is questionable whether the assumption of $b_{0}$ being equal for all size groups/types of trade is realistic. Hence, to study this question and 
as a compensation for leaving out the income elasticity as a indication of the product/service package, the influence of the sales composition is dealt with in the following way:

$$
G P=b_{01} Q_{1}+b_{02} Q_{2}+b_{03} Q_{3}+b_{04} Q_{4}+b_{1} K+b_{2}
$$

where:

$$
Q \triangleq Q_{1}+Q_{2}+Q_{3}+Q_{4} \text { and }
$$

$Q_{1}$ : value of food sales;

$Q_{2}$ : value of accommodation sales;

$Q_{3}$ : value of beverage sales;

$Q_{4}$ : value of non-food, non-accommodation and non-beverage sales, in this paper called 'remaining' sales. It contains sales revenue from tobacco, newspapers, etc. or that from entrance fees, commissions, etc.

Dividing both left and right terms of equation (4) by $Q$, our original 'percentage' specification now reads:

$$
m=b_{01} \frac{Q_{1}}{Q}+b_{02} \frac{Q_{2}}{Q}+b_{03} \frac{Q_{3}}{Q}+b_{04} \frac{Q_{4}}{Q}+b_{1} k+b_{2} \frac{1}{Q} .
$$

The above discussion leads to the following specification for testing our ideas:

$$
\begin{aligned}
m_{i t}= & b_{01} \frac{Q_{1 i t}}{Q_{i t}}+b_{02} \frac{Q_{2 i t}}{Q_{i t}}+b_{03} \frac{Q_{3 i t}}{Q_{i t}}+b_{04} \frac{Q_{4 i t}}{Q_{i t}}+b_{2} \frac{1}{Q_{i t}}+ \\
& +b_{11} k r_{i t}+b_{12} k c_{i t}+b_{3} k n_{i t}+b_{4}\left(k_{i t}-k n_{i t}\right)
\end{aligned}
$$

where:

$i \quad$ : index of the sales size interval;

$t$ : index of the year;

$m$ : average percentage gross margin;

$k$ : average percentage total operating costs excluding the reward for entrepreneurial labour;

$k r$ : average percentage actual operating costs;

$k c$ : average percentage calculated operating costs; note $k=k r+k c$;

$k n$ : average percentage normal operating costs;

$Q$ : average sales size in volume (in 1977 prices);

and $Q_{1} / Q, Q_{2} / Q, Q_{3} / Q$ and $Q_{4} / Q$ are the respective sales shares, see equation (4).

Evidently, coefficients $b_{11}$ and $b_{12}$ and coefficients $b_{3}$ and $b_{4}$ cannot be estimated simultaneously due to the fact that $k r+k c=k n+(k-k n)$. This will be further discussed in the next section.

Formally, the following hypotheses can now be tested:

$\mathrm{H} 1 \mathrm{The}$ average percentage gross margin is the result of a mark-up on total costs, i.e., $b_{11}=b_{12}=1$ or $b_{3}=b_{4}=1$. 
$\mathrm{H} 2$ In pricing behaviour a distinction is made between actual operating costs and calculated costs. The effects of this distinction can be measured comparing the values of $b_{11}$ and $b_{12}$. If $b_{11}=b_{12}$, both cost parts are equally important. If $b_{11}>b_{12}$, calculated costs are not passed on completely.

H3 In pricing behaviour a distinction is made between 'normal' operating costs and a short-term part of costs (containing business cycle, fortuitous, etc. effects). If $b_{3}>b_{4}$, the short-term part of total costs is not passed on completely.

H4 The gross profit margin depends on the product/service package offered and thus on the sales composition. The importance of this dependency can be reduced from differences in the values of $b_{01}, b_{02}, b_{03}$ and $b_{04}$.

H5 The mark-up contains a scale-dependent part, $b_{2}$. In the original version of Nooteboom's relationship, $b_{2}$ reflects an estimate of a basic, minimal reward for entrepreneurial labour.

\section{RESULTS}

To be able to test our hypotheses we first have to construct the variable normal costs, $k n$. This is done as follows (see also Nooteboom, Kleijweg and Thurik (1987)):

$$
k_{i t}=y_{0 i}+y_{1} T+y_{2} \dot{C} B_{i t}+u_{i x}
$$

where:

$k_{i t}$ : average percentage operating costs for size group $i$ in a certain trade group in year $t$

$T$ : dummy variable indicating year, $T=0$ for 1977 through $T=4$ for 1981 ;

$\dot{C} B_{i t}$ : percentage change of consumer spending (in volume), equal for all size groups per type of trade;

$u_{i t}$ : stochastic variable with zero mean and variance $s^{2} / n_{i t}$, where $n_{i t}$ is the number of establishments in size group $i$ in year $t$.

Normal costs are then defined as follows:

$$
k n_{i t}=\hat{y}_{0 i}+\hat{y}_{1} T
$$

$\hat{y}_{0 i}$ and $\hat{y}_{1}$ are the estimated values of the coefficients $y_{0 i}$ and $y_{1}$ in equation (7).

Proceeding in this way normal costs include a certain basic initial value, $y_{0}$, which may differ between size groups, and the linear time trend, $y_{1} T$, assumed to be equal for all size groups. They exclude trade cycle effects, $y_{2} \dot{C} B$, and fortuitous effects, $u_{i t}$, here assumed to have a random nature. In this way, normal costs are defined as a trend value of costs or as 'decycled' costs, per size group.

We mentioned earlier that it is not possible to test the contribution of actual and calculated costs and that of 'normal' versus total costs simultancously, 
when the total costs $(k)$ are defined to be the sum of the normal costs $(k n)$ and the short-term part $(k-k n)$. This singularity can be circumvented, replacing $b_{11} k r+b_{12} k c+b_{3} k n+b_{4}(k-k n)$ in equation (6) by

$$
b_{31} k n r+b_{32} k n c+b_{4}(k-k n)
$$

where $k n r$ and $k n c$ are average percentage normal actual operating costs and average percentage normal calculated operating costs defined in a manner similar to that explained in equations (7) and (8) and $k n r+k n c=k n$.

The calculations for obtaining $k n r$ and $k n c$ from equations (7) and (8) show an increase at a yearly rate of 1 to $1.5 \%$ for the three types of trade. In retailing, a time trend of about $0.4 \%$ has been found for the years 1976-1983 for 16 shoptypes together, see Nooteboom, Kleijweg and Thurik (1987). The values of the time trend for the hotel and catering sector appear to be high, but the period considered is characterized by a considerable price inflation, while the sector has been subjected to a restricted price policy from the government.

Equation (6) is estimated by weighted least squares. Disturbances $v_{\mathrm{it}}$ are added and they are assumed to be independently distributed with zero means and variance equal to $\sigma^{2} / n_{i t}$, where $n_{i t}$ is the number of establishments in size group $i$ in year $t$. It is doubtful whether our assumption of an independently distributed disturbance term is correct. Usually in panel studies the behaviour of the disturbances over cross-sectional units is assumed to differ from the behaviour of the disturbances of a given cross-sectional unit over time. The appropriate restrictions involved can be dealt with in various ways (see any econometrics textbook). We maintain our simple method in view of the short time series (5 years). Throughout our empirical tests special attention was devoted to systematic size group effects in the value of the residuals. Their occurrence could have been a warning against the appropriateness of our procedure. No such occurrence was established.

The following conclusions regarding the hypotheses formulated above can be drawn from Table 1, where estimation results using equation (6) are given: $\mathrm{H} 1: b_{11}$ (actual operating costs) does differ significantly from 1 for all types of trade. Also, $b_{12}$ (calculated operating costs) does differ significantly from 1 , as well as $b_{3}$ (normal costs) and $b_{4}$ (non-normal costs) for all types of trade. In fact all these coefficients are significantly less than 1 . The average percentage gross margin in the hotel and catering sector is not the result of a mark-up on costs. However, costs, no matter whether they are defined in terms of actual versus calculated or normal versus non-normal costs, generally have a significant influence in establishing prices.

$\mathrm{H} 2: b_{11}$ (actual operating costs) $>b_{12}$ (calculated operating costs) for all types of trade, though not significantly in all cases. $b_{12}$ does not differ significantly from zero in the case of the cafés. We conclude that it cannot be rejected that entrepreneurs in the hotel and catering sector base their price setting on actual operating costs rather than on total operating costs. 
TABLE 1 - ESTIMATION RESULTS PER TYPE OF TRADE (USING EQUATION 6)

\begin{tabular}{lllllllll}
\hline food & accom. & & bever. \\
sales & sales & rem. ${ }^{b}$ & 1 & $k r$ & $k c$ & $k n$ & $k-k n$ \\
$b_{01}$ & $b_{02}$ & $b_{03}$ & $b_{04}$ & $b_{2}$ & $b_{11}$ & $b_{12}$ & $b_{3}$ & $b_{4}$ \\
sales & $\bar{Q}$ & & & & \\
.55 & .78 & .46 & .14 & -.03 & .23 & .21 & & \\
$(.04)$ & $(.06)$ & $(.04)$ & $(.10)$ & $(.01)$ & $(.05)$ & $(.10)$ & & \\
.38 & .63 & .39 & .12 & -.06 & & & .43 & .10 \\
$(.07)$ & $(.07)$ & $(.04)$ & $(.08)^{*}$ & $(.01)$ & & & $(.08)$ & $(.06)^{*}$ \\
restaurants & & & & & & & & \\
.45 & & .52 & .04 & -.04 & .33 & .24 & & \\
$(.02)$ & & $(.03)$ & $(.06)^{*}$ & $(.01)$ & $(.03)$ & $(.07)$ & & \\
.43 & & .48 & .03 & -.05 & & & .36 & .23 \\
$(.02)$ & & $(.03)$ & $(.06)^{*}$ & $(.00)$ & & & $(.04)$ & $(.08)$ \\
cafés & & & & & & & & \\
.34 & & .61 & .09 & -.03 & .24 & .09 & & \\
$(.05)$ & & $(.03)$ & $(.04)$ & $(.02)^{*}$ & $(.04)$ & $(.13)^{*}$ & & \\
.32 & & .58 & .08 & -.05 & & & .28 & .13 \\
$(.04)$ & & $(.03)$ & $(.04)^{*}$ & $(.01)$ & & & $(.04)$ & $(.11)^{*}$ \\
\hline
\end{tabular}

a - estimated standard errors ( $(\hat{s})$ are printed beneath the estimated coefficients. An asterisk $\left({ }^{*}\right)$ is printed next to the standard error of coefficient $h$, if $|\hat{h}|<1.96 \hat{s}_{h}$ i.e. if $h$ is not significantly different from zero at $5 \%$ level of significance;

- the R-square, the coefficient of determination, is in excess of .99 in all cases and is not printed in the table.

b - accom., bever. and rem. sales stand for resp. accommodation sales, beverage sales and remaining sales (see p. 210, equation (4)).

H3: $b_{3}>b_{4}$ for all types of trade, though only significantly in the case of the hotels. $b_{4}$ differs significantly from zero only in the case of the restaurants. We conclude that entrepreneurs in the hotel and catering sector base their price setting on 'normal' costs rather than on total costs. In other words: short-term non-trend effects in costs are not (or are less) taken into account than normal (decycled) costs in price setting.

$\mathrm{H} 4: b_{01}, b_{02}, b_{03}$ and $b_{04}$ are in excess of 0 for all types of trade, whereas $b_{04}$ (remaining sales) does not differ significantly from zero in all but one case (cafés). We see that in the case of the hotels accommodation sales have the highest contribution to gross profits, and beverage sales in the cases of restaurants and cafés. We also see that remaining sales have the lowest contribution for all three types of trade. The contributions of beverage 
sales and food sales do not differ significantly for hotels, whereas for restaurants and cafés the contribution of beverage sales is significantly larger than that of food sales. The gross profit margin does depend on the sales composition for all types of trade considered in the hotel and catering sector.

$\mathrm{H} 5: b_{2}<0$ in all cases and significantly in all but one case. Apparently, $b_{2}$, being less than zero, cannot be interpreted as a coefficient for a (basic, minimal) reward for entrepreneur's labour. What we can conclude is that a scale effect occurs: the gross profit margin increases if average sales volume increases for all three types of trade.

Generally, coefficient estimates do not differ drastically between the three types of trade. Therefore, we perform a final estimation, grouping together all three types of trade. This enables the use of more explanatory variables, so that we can test simultaneously the contribution of actual and calculated costs and that of 'normal' versus 'non-normal' costs using equation (9). Also we want to test on the influence of the percentage change of consumer spending, $\dot{C} B$. For the three types of trade, different percentage changes have been calculated based on CBS (1980a, 1980b, 1980c, 1981, 1982 and 1983). For this test equation (6) is used, of which a part is replaced by equation (9) and $+b_{5} \dot{C} B$ is added. Estimation results are given in Table 2.

Obviously, the estimated coefficients do not differ much from those obtained per type of trade. However, we are now in a position to draw some general conclusions for the hotel and catering sector as a whole.

We see that accommodation sales have the highest contribution to gross profits, $\left(b_{02}=.71\right)$, followed by beverages $\left(b_{03}=.56\right)$ and food sales $\left(b_{01}=.46\right)$, whereas the contribution of remaining sales (including sales of tobacco, newspapers, other retail sales, entrance fees, etc.) is small $\left(b_{04}=.05\right)$ and not significantly different from zero. We conclude that differences in sales composition have a significant influence on the height of percentage margin in the hotel and catering sector (mark the small standard errors). Furthermore, it is questionable whether selling newspapers, tobacco, etc. and the provision

TABLE 2 - ESTIMATION RESULTS PER TYPE OF TRADE (USING EQUATION 6, OF WHICH A PART IS REPLACED BY (9) AND $+b_{5} \dot{c} b$ IS ADDED) ${ }^{\mathrm{a}}$

\begin{tabular}{cccccccccc}
\multicolumn{2}{l}{\begin{tabular}{l}
\multicolumn{2}{l}{ all types of trade } \\
food
\end{tabular}} & accom. & bever. & rem. & $\frac{1}{Q}$ & $k n r$ & $k n c$ & $k-k n$ & $\dot{C} B$ \\
sales & sales & sales & sales & $\frac{2}{Q}$ & & & & \\
$b_{01}$ & $b_{02}$ & $b_{03}$ & $b_{04}$ & $b_{2}$ & $b_{31}$ & $b_{32}$ & $b_{4}$ & $b_{5}$ \\
.46 & .71 & .56 & .05 & -.01 & .30 & .06 & .15 & -.08 \\
$(.01)$ & $(.03)$ & $(.02)$ & $(.03)^{*}$ & $(.01)^{*}$ & $(.02)$ & $(.07)^{*}$ & $(.05)$ & $(.03)$ \\
\hline
\end{tabular}

a see note to table 1 . 
of conference facilities (remaining sales) contribute significantly to percentage margin.

We also see that the influences of average percentage normal calculated costs $\left(b_{32}=.06\right)$ and that of non-trend effects $\left(b_{4}=.15\right)$ are less than that of average percentage normal actual operating cost $\left(b_{31}=.30\right) . b_{32}$ does not even differ significantly from zero. We conclude that the calculated part of costs and the short-term part have a smaller influence on percentage margin than normal actual costs.

Furthermore, we see that the effect of scale $\left(b_{2}=-.01\right)$ is not significant in this estimation. This is probably due to the high correlation between $1 / Q$ and $k n c$ (correlation coefficient $=.92$ ), which can be explained by the fact that the importance of family labour (calculated costs) decreases with increasing size. Also, in the estimation results per type of trade (Table 1), we see that $b_{2}$ is consistently lower when the partitioning $k r, k c$ occurs than when $k n,(k-k n)$ occurs. Nevertheless, considering all estimation results of $b_{2}$ in both Tables 1 and 2 , we see that $b_{2}$ is consistently negative, which implies that there is a positive relation between average size and percentage margin, ceteris paribus.

Finally, we see that the influence of consumer spending $\left(b_{5}=-.08\right)$ is negative and hence contrary to what is expected. We shall further discuss this result in our conclusions.

\section{CONCLUSIONS}

Differences in average percentage gross profit margin between size groups as well as its development in time can be explained rather well by our model for three types of trade covering the entire hotel and catering business. The types of trade are hotels, restaurants and cafés in the Netherlands and the period considered runs from 1977 through 1981.

Differences in gross margin are primarily explained by the composition of sales in the sense that, ceteris paribus, fixed contributions to gross profit margin exist for the various sales components. We do not have a plausible explanation of the height of the coefficients of the various sales components. Percentage costs play a significant role in the establishment of average percentage gross margin but not in the sense that a mark-up model obtains. Productivity gains or losses are passed on only partially in pricing.

In this study we discriminate between actual and calculated costs. Calculated costs involve costs associated with depreciation, family labour, etc. In addition, we discriminate between normal (trend) costs and a short-term part of costs (containing business cycle and fortuitous effects). The influence of actual costs is smaller for hotels and cafés than for restaurants. A ceteris paribus increase (decrease) of one percentage point of average percentage actual operating costs gives an increase (decrease) of about a .23 percentage point average percentage gross margin for hotels and cafés and of a .34 percentage point for restaurants. On the whole, we see that both non-normal costs and calculated costs play a 
less important role in the establishment of prices than normal actual costs.

A scale effect in the explanation of gross margin is consistently found: average percentage gross margin increases with increasing average establishment size (expressed in terms of yearly sales). This effect is probably due to the following: price elasticity drops with increasing service level and service level increases with increasing average scale. See also Van der Hoeven and Thurik (1986). This hypothesis needs further testing.

Finally, we shall deal with the demand effects found in our study. The demand condition test is justified by the hypothesis that '...in a contracting market, price competition is more intense, in the fight for a larger share in the declining market, in the attempt to sustain sales volume' (see Nooteboom (1985) p. 651). Nooteboom (1985) reports a significant demand effect using Dutch grocery data (1957 through 1979). Nooteboom and Thurik (1985) report asymmetries on the bais of Dutch retail data for the period 1976-1982 for 16 shop-types: the hypothesis is supported in declining markets, but not in growing markets. Nooteboom, Kleijweg and Thurik (1987) discuss and test the occurrence of demand effects depending upon whether normal costs or total costs are used in the mark-up equation, because demand effects are likely to influence the discrepancy between normal and total costs. They conclude that the coefficient of $k-k n$ is about half that of $k n$ (the latter being approximately one) and that a 'positive' demand effect occurs for demand growth, but not for declining demand. In our study of the hotel and catering sector we see that the coefficient of $k-k n$ is also about half that of $k n$ (the former being approximately .15, see Table 2) and that a significant 'negative' demand effect occurs. Unfortunately, there are not enough observations to test for asymmetries. We conclude that declining (growing) demand yields short-term costs above (below) their trend value (procyclical productively hypothesis) and this (dis)advantage is passed on for only approximately $50 \%$ in the gross margin. The fact that percentage gross margins show an additional counter-cyclical ("negative' demand) effect $\left(b_{5}<0\right.$ in Table 2$)$ may be due to the fact that purchase prices probably correlate with the business cycle. And we know from the definition of gross margin (section 3) that gross margin is inversely related to purchase prices.

An alternative explanation for the 'negative' demand effect is the following. There is a certain correlation between the development in consumer spending, $\dot{C} B$, and the development of the number of establishments due to low entry barriers and the occurrence of only moderate scale economies on the establishment level. See Van der Hoeven and Thurik (1986). If the development of the number of establishments has an effect on prices in the sense that there is pressure on prices if this number increases (increased price competition), $\dot{C} B$ might act as indicator for increased price competition. There is room to further investigate demand and environmental effects on pricing within the framework of our model. 


\section{REFERENCES}

Anthea Rogers, H., 'Pricing in Hotels,' in: R. Kotas (ed.), Managerial Economics for Hotel Operation, London, 1980.

Bode, B., J. Koerts and A.R. Thurik, 'On Storekeeper's Pricing Behaviour,' Journal of Retailing, 62 (1986), pp. $98-110$.

CBS (Central Bureau of Statistics), Produktiestatistieken Commerciële Dienstverlening, hotels 1977 en 1978, The Hague, 1980a.

CBS (Central Bureau of Statistics), Produktiestatistieken Commerciële Dienstverlening, maaltïdverstrekkende bedrijven 1977 en 1978, The Hague, $1980 \mathrm{~b}$.

CBS (Central Bureau of Statistics), Produktiestatistieken Commerciële Dienstverlening, drankenverstrekkende bedrijven 1977 en 1978 , The Hague, $1980 \mathrm{c}$.

CBS (Central Bureau of Statistics), Produktiestatistieken Commerciële Dienstverlening, hotels, restaurants, cafés, etc. 1979, The Hague, 1981.

CBS (Central Bureau of Statistics), Produktiestatistieken Commerciële Dienstverlening, hotels, restaurants, cafés, etc. 1980, The Hague, 1982.

CBS (Central Bureau of Statistics), Produktiestatistieken Commerciële Dienstverlening, hotels, restaurants, cafés, etc. 1981, The Hague, 1983.

Dutkowsky, D.H. and D.J. Gianturco, 'On the Inflation-unit Labor Cost Relation,' Journal of Economics and Business, 38 (1986), pp. 173-181.

Gershuny, J.I. and I.D. Miles, The New Service Economy: The Transformation of Employment in Industrial Societies, London, 1983.

Hest, P.B. van, 'Methoden van verkoopprijsbepaling in de horeca', Hotelrevue, 10 (1983), pp. I4 15.

Hoeven, W.H.M. van der, and A.R. Thurik, Een vergelijking van de loonkosten yoor ondernemingen in de horecasector: een berekeningsmethode voor het 'gewaardeerd' ondernemersloon, Researchpublicatie nr. 10, Research Institute for Small and Medium-Sized Business, Zoetermeer, 1985.

Hoeven, W.H.M. van der, and A.R. Thurik, Een arbeidsvraagrelatie in de horecasector, Researchpublicatie nr. 17, Research Institute for Small and Medium-Sized Business, Zoetermeer, 1986.

Keller, F.E., Preispolitik der Hotellerie, Bern, 1970.

Kotas, R., Market Orientation in the Hotel and Catering Industry, London, 1975.

Kotler, Ph. and P.N. Bloom, Marketing Professional Services, Englewood Cliffs (N.I.), 1984.

Kreul, L.M., 'Magic Numbers, Psychological Aspects of Menu Pricing,' Cornell Hotel and Restazrant Administration Quarterly, 23 (1982), pp. $70-76$.

Lovelock, C.H., Services Marketing, Englewood Cliffs (N.J.), 1984.

Nooteboom, B., 'A Mark-up Model of Retail Margins,' Applied Economics, 17 (1985), pp. 647-667.

Nooteboom, B. and A.R. Thurik, 'Retail Margins During Recession and Growth,' Economics Letters, 17 (1985), pp. 281-284.

Nooteboom, B., A.J.M. Kleijweg and A.R. Thurik, Normal Costs and Demand Effects in Price Setting: A Study of Retailing', in: European Economic Review, 1987, for thcoming.

Nooteboom, B., A.R. Thurik and J.A.C. Vollebregt, 'Les marges de la distribution de detail, diffèrent-elles entre les pays européens?,' Revue Française du Marketing, 106 (1986), pp. 63-74.

Rathmell, J.M., Marketing in the Service Sector, Cambridge (MA.), 1974.

Snel, D., Structuur en ontwikkeling van de commerciele dienstensector in Nederland, Research Institute for Small and Medium-Sized Business, Zoetermeer, 1986.

Sylos-Labini, P., 'Prices and Income Distribution in Manufacturing Industry,' Journal of PostKeynesian Economics, 2 (1979), pp. 3-25. 
Thurik, A.R. and A.J.M. Kleijweg, 'Procyclical Retail Labour Productivity,' Bulletin of Economic Research, 38 (1986), pp. 169-175.

Weintraub, S., Capitalism's Inflation and Unemployment Crises: Beyond Monetarism and Keynesianism, Reading (MA.), 1978.

\section{Summary}

\section{PRICING IN THE HOTEL AND CATERING SECTOR}

A model explaining gross margins in the hotel and catering sector is developed. A cost-mark-up model for the retail sector is used as a starting point. Although we have to reject the hypothesis of mark-up pricing in the hotel and catering sector, the model proves a useful instrument to discriminate between such influences as sales composition, costs and their various components, scale and demand conditions on price setting. Our empirical evidence stems from the Dutch hotel and catering sector (1977 through 1981). 